\title{
Predictors of the Use of E-Medicine by Medical Doctors
}

\section{Gbolahan Olasina ${ }^{1 *}$ and Tobi Popoola ${ }^{2}$}

${ }^{1}$ Faculty of Communication and Information Sciences, PMB 1515, University of Ilorin, Nigeria

${ }^{2}$ General Hospital Aliade, Gwer East Local Government, Aliade, Benue State, Nigeria

\begin{abstract}
Background and objectives: Recent developments have continued to challenge the myriad of reasons that healthcare has not been automated as much as education, industry or banking. Some of which may be that healthcare is very personal. However, the introduction of clinical decision systems has continued to grow in the developed world and very recently in developing countries such as South Africa and Nigeria. The purpose of this study was to explore the use of e-medicine at 3 tertiary hospitals in Nigeria. The study determined the predictors of doctors' use of e-medicine. It explored the evidence of the adoption and the use of ICT by the doctors and medical doctors in Nigeria.

Methods: A quantitative method using survey research design was adopted in line with a positivist paradigm. Survey questionnaire was used for data collection. A test-retest reliability was embarked upon to determine the reliability of the questionnaire. A statistical package for social sciences (SPSS) was used to analyze the data and methods of analysis included descriptive statistics, mean, standard deviation and multiple regression analysis.

Results: The results revealed key and emerging variables for the extension of the Unified Theory of Acceptance and Use of Technology model (UTAUT) to better explain doctors' use of e-medicine. The study revealed that fear and lack of e-medicine awareness are responsible for the low use rates of e-medicine and suggested that strategies, devises and interventions should be introduced to induce the use of e-medicine.
\end{abstract}

Keywords: E-medicine; Health information systems; Use of technology; Medical doctors; Nigeria

\section{Introduction}

In order to achieve country-wide e-medicine awareness, interoperability and realize the relative benefits of ICT to curb poor health services delivery in Nigeria, doctors 'use rates of e-medicine must be increased substantially. However, it is essential to implement the right ICT tools the right way and to ensure that the e-medicine has a high success rate for both doctors and the patients. Catwell et al. [1] and Wears et al. [2] reported the failure of a large chunk of health information technology projects in medical-based information science (IS) literature. An understanding of the predictors of doctors' use of e-medicine will allow the administrators of health institutions to better assess system readiness and facilitate successful implementation of e-medicine projects and initiatives. The purpose of the present study was to determine the factors that predict doctors' e-medicine use.

How and why individuals adopt innovations has motivated a great deal of research. This study examined the doctors' and other medical staffs' e-medicine use processes through a grounding of the Unified Theory of Acceptance and Use of Technology (UTAUT) model. Technology adoption is a complex, inherently social, developmental process that individuals-medical doctors construct unique yet flexible perceptions of technology that influence their use decisions [3]. Facilitating technology use success in the context of medical professions must address cognitive, emotional, and contextual concerns. This study focused specific attention on technology use by the medical doctors in Nigeria which is not commonly reported in literature [4].

Several researchers have reported poor infrastructures in Nigeria and much of sub-Saharan Africa that have caused these countries to suffer from the lack of efficient and effective delivery of basic and extended medical and healthcare services [5-7]. Eno [6] highlighted that often, such limitations are further accompanied by low patient-doctor ratios, resulting in unwarranted rationing of services, in-availability of doctors and other medical staff, poor funding and the lack of drugs, often resulting in medical facilities becoming redundant. E-medicine awareness among the politicians, policy makers and medical doctors is motivating the gradual adoption and the use of ICT in Nigeria. There still is a wide gap between recent e-medicine approaches and systems in the developing countries and the existing ICT infrastructure leading to faulty, inefficient and poor take off of the e-medicine in Nigeria. The case of the adoption and the use of e-medicine in the context of Nigeria is one that carries with it great prospects hence the need for the present investigation to determine the predictors of the use of e-medicine by doctors in Nigeria [8,9].

E-medicine in this study refers to the use of computers for support in information processing, decision making and records keeping and other information and communications technology applications in the health sector which is dependent on the level of adoption and use by health professionals especially the doctors. The issue of the use of ICT to manage patients at a distance (telemedicine), manage hospitals and their patients' records and search and retrieve pertinent information for research and assist in clinical decision making, is well researched in literature as several authors $[10,11]$ have reported that clinical practice has been tremendously improved by the adoption and use of ICT or health informatics. Asangansi et al. [12] reported that not much is reported in literature about the adoption and use of e-medicine among doctors in Nigeria.

Authors [13] described e-medicine as the provision of medical information by way of Web-enabled technology which may fast be

*Corresponding author: Gbolahan Olasina, Faculty of Communication and Information Sciences, PMB 1515, University of Ilorin, Nigeria, Tel: 08033292529; E-mail: gbolasina@yahoo.com, olasina.g@unilorin.edu.ng

Received August 28, 2014; Accepted September 24, 2014; Published October 01, 2014

Citation: Olasina G, Popoola T (2014) Predictors of the Use of E-Medicine by Medical Doctors. J Health Med Informat 5: 166. doi:10.4172/2157-7420.1000166

Copyright: @ 2014 Olasina G, et al. This is an open-access article distributed under the terms of the Creative Commons Attribution License, which permits unrestricted use, distribution, and reproduction in any medium, provided the original author and source are credited. 
replacing or complementing the more traditional ways people seek medical advice and information. These Web based medical platforms are aimed at the understanding of the potential service and to the making of informed decisions. With e-medicine, individuals and groups can contact family, friends or their medical doctors to ascertain their medical conditions and receive medical attention using the medium of the Internet in the comfort of their homes. The credibility and authentication of e-medicine services can be very high as a result of peer reviewed contents aimed at reaching high standards of services for users of e-medicine platforms.

It is reported that the doctors know very little about e-medicine $[14,15]$. The researchers $[16,17]$ traced the beginnings of e-medicine to the US and New Zealand as involving the process when online doctor visits began to mark medicine in 2009 with 9 million US adults emailing their doctors. E-medicine was initiated by the support of the American Medical Association for the use of online evaluation services between a doctor and an established patient. The concept of e-medicine is the provision of medical advice by e-mail, telephone and video conferences, to link patients directly to providers of health care services [18]. E-medicine involves the ability to synergize all stages in the medical processes such as surgery, diagnosis, in-patient and outpatient care into a single e-medicine platform such that doctors and other medical professionals collaborate and share data via a one-stopshop platform for multiple services on a network [19]. The relative advantage of e-medicine is that it enables doctors and other medical staff, patients to access their medical information needs either online or via emails or other online communities $[20,21]$.

Abd Ghani et al. [22] in a study carried out in 2002 among a selected population of student doctors in Malaysia reported that $94.3 \%$ of respondents could use a computer. Similarly higher values have been obtained for medical/dental students in Europe and Saudi Arabia $[23,24]$. A study carried out in New Zealand and Denmark showed that $99 \%$ of practices use specifically designed patient management system software to assist with recording of patient and clinical consultation details and to help with the daily running of their businesses [25]. Bennett et al. [26] reported a survey of physicians across eleven North American, European and Asian countries in 1998 where $80 \%$ of physicians were found to own a computer and $44 \%$ of these physicians had accessed the Internet. Their predominant mode of access was the Internet in the home. Recent studies have however shown remarkable improvements in these figures $[27,28]$.

\section{E-medicine in Nigeria}

The authors $[29,30]$ provide a background of the practice of medicine and health services in the context of Nigeria. The provision of adequate health services to a highly populated country like Nigeria is fraught with constraints such as financial and manpower resources like many developing countries. The often few available facilities are unevenly distributed suggesting that health improvement planning in Nigeria should rather focus on making the limited facilities most efficient and functional. The issue of manpower shortcomings is alarming with only a very few medical doctors available in ratio to hundreds of thousands of citizens. There is the issue of dilapidation of infrastructure and failure of health information and ailing health records management [29]. It is against this background that the present study conducted a survey of doctors and medical the potentials of e-medicine to complement the field of medicine and the practice of medicine by doctors in Nigeria.

Several researchers [31-33] have reported that the use of Web applications in Nigeria seems to grow from a general spectrum of Web applications in activities such as learning, banking, industry and governance. In a series of healthcare related studies conducted in Nigeria by [34] Bello, Arogundade, Sanusi, Ezeoma, Abioye-Kuteyi and Akinsola cited by Asangansi et al. [12], the studies report that from a sample of doctors only about $0.5 \%$ of doctors searched the Internet for information relating to their clinical practice/research, although $72 \%$ of respondents believed that the Internet had a role to play in medical practice. The report of a survey of health professionals and medical students in the Lagos area of Nigeria revealed that only $26 \%$ of respondents had a computer or laptop and only $27 \%$ of the doctors demonstrated computer literacy. The personal skills and information-handling competencies of the respondents showed that many of the respondents could not use word processing software while $87 \%$ indicated that they could not use any software for basic statistical analysis. Only (97) of the respondents develop their own Microsoft PowerPoint slides for presentation. A large number (115) could use MEDLINE/Pubmed but only (57) had published a paper. A number of 107 of the respondents answered that the paper-based system hampered research while even a larger number (129) thought that the computer-based system will be a better system. Some of the respondents (2) thought otherwise whilst (14) were undecided. The major reason given by the respondents on why the computer-based system was better was as a result of improved accessibility of records to doctors, some felt that in the long run, the computer based system will save cost and that parts of the records from different departments could more easily tracked. The field of medicine and medical practice requires the use of computers for support in information processing, decision making and records keeping [35-37]. Asangansi et al. [12] concluded that the success of information and communications technology applications in the health sector is dependent on the level of computer use by health professionals especially the doctors. The present study included only medical doctors. Whereas, previous studies [38] were not underpinned by any theoretical paradigms the present study was theoretically guided by a recently synthesized model of technology adoption. The study was based on the Unified Theory of Acceptance and Use of Technology (UTAUT) model. The study utilized a survey questionnaire (Appendix) that assessed the level of e-medicine use by medical doctors in three Nigerian tertiary teaching hospitals, the University College Hospital, (UCH), Ibadan, the Obafemi Awolowo Teaching Hospital, Ile Ife, (OAUTHC) and the University of Ilorin, Teaching Hospital, Ilorin, (UITH), all located in Nigeria. The study explored the perceptions of the doctors of the use of medical recording systems and ICT based medical services delivery applications in their medical practice. The study is planned to be carried out similarly in other places such as South Africa. This survey served as a pilot study.

\section{Research Questions}

The purpose of the study was to investigate the predictors of the use of e-medicine by doctors in Nigeria. The critical questions of the study were the following:

1. What are the predictors of the use of e-medicine by medical doctors?

2. To what extent do doctors adopt the use of e-medicine?

3. What are the inhibitors to the use of e-medicine by the medical doctors?

\section{Theoretical Framework}

A number of theories have been suggested to describe the hospital 
behaviour and the adoption of new technology, yet these theories are not mutually exclusive and none of these perspectives alone has been able to satisfactorily explain technology adoption [39,40]. The first set of models known as the profit maximization model or the price competition model or the fiscal managerial system uses traditional economic theory to explain hospital behaviour [41,42]. This approach assumed that hospitals evaluate ICT tools from the perspective of hospital profitability [39]. In recent time technology acceptance models such as the Theory of Planned Behaviour (TPB) and the Technology Acceptance Model (TAM) have been used in many studies $[43,44]$ to explain the phenomenon. Bagozzi $[40,45,46]$ has criticized the use of these early technology acceptance models and particularly describing the TAM as non-specific, inadequate in measuring system usage, the absence of sound theory/method for measuring perceived usefulness (PU) and perceived ease of use (PEOU), the disregard for societal factors that affect the predictors of adoption and the use of technology. Based on these criticisms, the present study was based on the adaptation of the UTAUT (Unified Technology Acceptance and Use of Technology model) by [47] which is a more recent instrument synthesized from eight existing models of use of technology that include the Technology Acceptance Model (TAM), the Theory of Reasoned Action, the Motivational Model, the Theory of Planned Behaviour (TPB) - a combination of the Technology Acceptance Model (TAM) and the TPB model, the Model of PC Utilization, the Innovation Diffusion Theory and the Social Cognition Theory [48]. The UTAUT has been tested in several studies in the context of SMEs, industry, banking, learning and government but very limited studies have applied the UTAUT in the context of medical practice. The present study attempted to apply the UTAUT in the context of medical practice in Nigeria. The attributes of the UTAUT are effort expectancy, performance expectancy, social influence and facilitating conditions. These attributes are linked directly to the critical questions addressed in this study. To enhance the robustness of the UTAUT and to better explain the predictors of doctors' use of e-medicine, additional variables such as accessibility, trust, cost, government policy and security, factors peculiar to a developing country such as Nigeria are used to extend the UTAUT [49-51]. The point of departure from the cited studies is that extensions of the UTAUT model have hardly been used to explain technology adoption and use by medical doctors in Nigeria.

\section{Literature Review}

Danskyetal. [52] evaluated the attitudes of doctorstowardselectronic health records (EHR) adoption before and after implementation and reported that very few studies exist in IS literature in this area. The authors reported that the variables like perceived usefulness, computer experience, patient care values and organizational support positively influenced the doctors' attitudes to the use of the EHR. Another author Ganapathy [53] in a more recent study highlighted the areas of e-health and clinical applications to include the following:

"Electronic Health Records, Tele Consultations, Clinical Decision Making Support Systems, Vital Signs Monitoring Services, Tele Home Care, Ambulatory e-Health-smart clothing, e-Wear, e-Clothing, ePrescribing, e-Nursing, e-dissemination of personalized healthcare and professional Continuing Education using e-Learning tools: Health Information Systems, LifeTime Health Records/EMR, Pharmacy Information Systems, Electronic Claims Systems, Laboratory Information Systems, Interfacing with Diagnostic Equipments, ICT in Health Administration, and Identification and Tracking Solutions".

van der Meijden et al. [54] reported that computer experience predicted the adoption of e-health by the doctors and other medical professionals. These studies were conducted in developed countries. The findings from these studies suggest that the predictors of medical doctors' adoption and the use of ICT could depend on whether the country of study is developed or developing. Based on these considerations, the present study was embarked upon to determine the predictors the use of e-medicine by medical doctors in Nigeria.

Buysschaert [55] theorized that with e-medicine, patients will increasingly be responsible for their own health. The patients will have real time access to electronic information on new technologies and treatments will make them empowered patients. They will not just be checking their BP and blood sugar but critically reviewing different treatment options and medicine of the future will be wireless such as mHealth and telemedicine. The author [55] surveyed e-medicine in the developing countries and reported that many reasons can be stressed why eHealth technologies could be welcome in developing countries and these ranged from the issues of critical shortage of health workers to the challenges of HIV and poor sanitary conditions [56]. The researcher identified three roles that e-medicine can play in the developing countries. These include telecounselling and distance learning. Lastly, the researcher explained that eHealth can contribute to the support of auxiliary health workers, such as nurses and midwives. Buysschaert [55] reported that e-medicine platforms were at varying stages of start up in developing countries such as Kenya, Brazil and Peru, South Africa and India. The lack of education and mass illiteracy in Nigeria may make e-medicine a difficult possibility for the public but the views of the medical doctors were sought to determine their attitudes, perceptions and use of e-medicine. This was carried out by investigating the factors that influence the doctors to use e-medicine.

Ruxwana et al. [57] suggested that technology based solutions like e-health, telemedicine and e-education are often viewed as the instruments to bridge the digital divide between rural and urban healthcare centres and to ameliorate the shortfalls of the rural health care in most developing countries. The researchers focused on the factors perceived to influence the use of ICT such as e-health solutions in selected rural Eastern Cape areas of South Africa. The study reported that for the use rates of e-medicine to increase much attention must be given to increase the usefulness and ease of use of e-medicine by the medical doctors.

In summary, the review of literature indicated that the variables like perceived usefulness, computer experience, patient care values and organizational support predict medical doctors' decisions to use e-medicine in the context of the developed countries. Previous literature suggest that several studies on the phenomenon have been carried out on the prospects of e-medicine based on technical factors (ICT infrastructure, accessibility and availability) but very little exists in literature on the human factors that influence technology adoption by medical doctors in Nigeria.

\section{Research Methods}

A positivist paradigm was adopted. A quantitative method was employed and this was based on the review of related literature $[58,59]$. The data collected were analyzed and presented in the form of tables, frequency counts, percentages and Pearson Product Moment Correlation Analysis (PPMC) using the Statistical Package for Social Scientist (SPSS). A random sample of 120 medical doctors, dentists and pharmacists from the three tertiary health institutions was selected for the survey. The study used a survey questionnaire. There are fifty-three federal tertiary hospitals in Nigeria, that is, Nigeria's teaching hospitals, 
federal medical centres and national eye centres. The population for this study was drawn from the doctors at the federal tertiary hospitals. Out of the federal tertiary hospitals, three were purposively drawn, the Obafemi Awolowo University Teaching Hospital (OAUTHC), Ile Ife, Osun State, The University College Hospital ( $\mathrm{UCH})$, Ibadan and the University of Ilorin Teaching Hospital (UITH). The number of doctors at each of these three institutions is: OAUTHC - 600, UCH- 1000 and UITH -600 . From these three institutions, simple random sampling technique was used to select thirty-eight medical doctors each from OAUTHC and UCH and twenty-seven for UITH, respectively. The construction of the survey questionnaire was based on the review of literature and the fall-outs of a pilot-test of the instrument on sixteen medical students. Each item of the survey questionnaire was measured using a five-point Likert scale that ranged from 'strongly disagree' to 'strongly agree'. The items in the survey questionnaire were drawn from the review of related literature (Grzywacz, Lang, Suerken, Quandt, Bell and Arcury, 2005; Byrne, Elliott and Firek, 2009) or based on the constructs of the UTAUT model that was the theoretical framework for the study. The survey questionnaire was used as the instrument of data collection and designed with mainly close-ended question items in line with the adopted paradigm. Construct validity was achieved by a factor analysis that was performed using a method of principal component analysis. It was found that the results obtained were similar to those of the original instruments that were adapted for the current study. The exploratory factor analysis examined the factor structure of the 10-item questionnaire. Prior to this time, a chi-square value of 5903.91and significant level of 0.05 were obtained. This suggested that the inter-correlation matrix contains sufficient common variance to make the factor analysis worthwhile. The extraction of principal component factor analysis and iterative sequence techniques were used. It was only at this stage that 10 predictor factors were retained and no further deletions made. In summary, the factor analysis returned 10 factors and these were: age, behavioural intention, ICT skills, performance expectancy (perceptions), effort expectancy, social influence, facilitating conditions, trust, access and applicability. These 10 factors explained $75 \%$ of the variance in the data set. No cross loading was found. The significant loading of all the items on the single factor indicated uni-dimensionality. It was observed that no crossloading was found. Thereafter, the predictors were tested for reliability, using a Cronbach Alpha test. Nunnally [60] suggested that the score for each construct should be greater than 0.6 to be considered reliable. The Cronbach Alpha (reliability) ranged from 0.8 to 0.9 . Because the overall reliability of measurement was above 0.7 , the measurement instrument was deemed to have sufficient internal consistency. Thereafter, the data were found to be appropriate for further analysis. The survey was conducted between October and December 2011. The response showed that $103(85.8 \%)$ questionnaire were returned completed and analyzed.

\section{Results and Discussion}

A total number of 103 responses were utilized in the analysis. The demographic profile of the respondents is shown in Tables 1-6. Table 1 shows the breakdown of the respondents based on the 3 tertiary health institutions. The OAUTHC and UCH have $36.9 \%$ of the participants. Table 2 shows the range of medical doctors that took part in the survey and there specializations ranged from cardiologists, consultants, dentists, house officers and hematologists. All the respondents including the registrars are practicing medical doctors and not in administrative capacities. With regard to gender, females dominated (63.1\%) over males $(35.9 \%)$ as indicated in Table 3. In terms of age, (Table 4) the respondents are $(29.1 \%)$ within the age group of $31-40$ years and the

\begin{tabular}{|l|l|l|l|l|l|}
\hline \multicolumn{2}{|c|}{} & Frequency & Percent & $\begin{array}{l}\text { Valid } \\
\text { Percent }\end{array}$ & $\begin{array}{l}\text { Cumulative } \\
\text { Percent }\end{array}$ \\
\hline \multirow{4}{*}{ Valid } & OAUTHC & 38 & 36.9 & 36.9 & 36.9 \\
\cline { 2 - 6 } & UCH & 38 & 36.9 & 36.9 & 73.8 \\
\hline \multirow{4}{*}{ UITH } & 27 & 26.2 & 26.2 & 100.0 \\
\hline Total & 103 & 100.0 & 100.0 & \\
\hline
\end{tabular}

Table 1: Name of Institution $\mathrm{N}=103$

\begin{tabular}{|l|c|c|}
\hline Medical Professional & Frequency & Percentage \\
\hline Cardiologist & 1 & 1 \\
\hline Cardiotherasic & 1 & 1 \\
\hline Consultant & 5 & 4.9 \\
\hline Dentist & 4 & 3.9 \\
\hline Anesthesiologists & 24 & 1 \\
\hline House Officer & 2 & 23.3 \\
\hline GP & 4 & 1.9 \\
\hline Gynecologist & 2 & 3.9 \\
\hline Immunologists & 3 & 1.9 \\
\hline Houseman & 6 & 2.9 \\
\hline Intern & 6 & 5.8 \\
\hline Medical Officer & 1 & 5.8 \\
\hline Neuro-surgeon & 6 & 1.0 \\
\hline Opthamologist & 1 & 5.8 \\
\hline Obstetricians & 1 & 1.0 \\
\hline Psychiatrist & 1 & 1.0 \\
\hline Radiologist & 14 & 1.0 \\
\hline Registrar & 10 & 13.6 \\
\hline Resident & 1 & 9.7 \\
\hline Hematologists & 8 & 1.0 \\
\hline Senior reg & 1 & 7.8 \\
\hline Surgeon & 2 & 1.0 \\
\hline Urologist & 103 & \\
\hline Total & 1.0 \\
\hline & 1 & \\
\hline
\end{tabular}

Table 2: Medical Doctors $\mathrm{N}=103$.

\begin{tabular}{|l|l|l|l|l|l|}
\hline \multicolumn{2}{|c|}{} & Frequency & Percent & $\begin{array}{l}\text { Valid } \\
\text { Percent }\end{array}$ & $\begin{array}{l}\text { Cumulative } \\
\text { Percent }\end{array}$ \\
\hline Valid & Female & 65 & 63.1 & 100.0 & 100.0 \\
\hline \multirow{3}{*}{ Missing } & Male & 37 & 35.9 & & \\
\cline { 2 - 6 } & System & 1 & 1.0 & & \\
\cline { 2 - 6 } & Total & 38 & 36.9 & & \\
\hline Total & & 103 & 100.0 & & \\
\hline
\end{tabular}

Table 3: Gender N=102.

rest roughly evenly distributed from 21 to 30,41 to 50 and 51 and above years. With regard to length of medical practice (Table 5), most of the respondents are 16 years and over in medical practice (28.2\%), 6 to 10 years $(25.2 \%), 1$ to 5 years $(24.3 \%), 11$ to 15 years (12.6\%) and less than one year $(9.7 \%)$. Table 6 indicates the respondents' level of ICT skills with (53.4\%) having basic skills, $(34.0 \%)$ at the beginner stage, $(11.7 \%)$ are at the intermediate level and (1.0\%) at advanced ICT skills' level. This result suggests that it may be almost impossible to implement and use ICT based medical systems at the moment. Perhaps, an extensive training programme should be first provided to the medical doctors and other stakeholder before e-medicine systems is introduced. Despite, these results, all the respondents indicate ownership of smart phones and either a desktop or laptop. Many others owned i-pads, PDAs, i-phones, BBMs and i-tabs. The radiologists indicate using EHR systems CT and MRI scanners suggesting the availability of some technologies in the tertiary hospitals. 


\begin{tabular}{|l|l|l|l|l|l|}
\hline \multicolumn{2}{|c|}{} & Frequency & Percent & Valid Percent & $\begin{array}{l}\text { Cumulative } \\
\text { Percent }\end{array}$ \\
\hline Valid & $21-30$ & 25 & 24.3 & 24.3 & 24.3 \\
\hline & $31-40$ & 30 & 29.1 & 29.1 & 53.4 \\
\hline & $41-50$ & 24 & 23.3 & 23.3 & 76.7 \\
\hline & 51 and $>$ & 24 & 23.3 & 23.3 & 100.0 \\
\hline & Total & 103 & 100.0 & 100.0 & \\
\hline
\end{tabular}

Table 4: Age $\mathrm{N}=103$.

\begin{tabular}{|l|l|l|l|l|l|}
\hline \multicolumn{2}{|c|}{} & Frequency & Percent & $\begin{array}{l}\text { Valid } \\
\text { Percent }\end{array}$ & $\begin{array}{l}\text { Cumulative } \\
\text { Percent }\end{array}$ \\
\hline \multirow{4}{*}{ Valid } & $<1$ year & 10 & 9.7 & 9.7 & 9.7 \\
\cline { 2 - 6 } & $1-5$ years & 25 & 24.3 & 24.3 & 34.0 \\
\hline \multirow{4}{*}{ 6-10 years } & 26 & 25.2 & 25.2 & 59.2 \\
\hline \multirow{4}{*}{$11-15$ years } & 13 & 12.6 & 12.6 & 71.8 \\
\hline \multirow{2}{*}{16 years and $>$} & 29 & 28.2 & 28.2 & 100.0 \\
\hline Total & 103 & 100.0 & 100.0 & \\
\hline
\end{tabular}

Table 5: Length of medical practice $\mathrm{N}=103$.

\begin{tabular}{|l|l|l|l|l|l|}
\hline \multicolumn{2}{|c|}{} & Frequency & Percent & $\begin{array}{l}\text { Valid } \\
\text { Percent }\end{array}$ & $\begin{array}{l}\text { Cumulative } \\
\text { Percent }\end{array}$ \\
\hline \multirow{4}{*}{ Valid } & Basic & 55 & 53.4 & 53.4 & 53.4 \\
\cline { 2 - 6 } & Beginner & 35 & 34.0 & 34.0 & 87.4 \\
\hline \multirow{4}{*}{ Intermediate } & 12 & 11.7 & 11.7 & 99.0 \\
\hline \multirow{2}{*}{ Advanced } & 1 & 1.0 & 1.0 & 100.0 \\
\hline & Total & 103 & 100.0 & 100.0 & \\
\hline
\end{tabular}

Table 6: Level of ICT skill $\mathrm{N}=103$.

\begin{tabular}{|l|l|c|c|c|c|c|}
\hline \multicolumn{2}{|l|}{ Model } & \multicolumn{2}{|c|}{$\begin{array}{c}\text { Unstandardized } \\
\text { Coefficients }\end{array}$} & $\begin{array}{c}\text { Standardized } \\
\text { Coefficients }\end{array}$ & & \\
\cline { 3 - 7 } \multicolumn{2}{|c|}{1} & B & Std. Error & Beta & t & Sig. \\
\hline & (Constant) & 3.981 & 1.431 & & 2.781 & .007 \\
\hline & AGE & -.058 & .128 & -.031 & -.450 & .655 \\
\hline BI & -.212 & .112 & .153 & -.621 & .067 \\
\hline ICTSKILL & -.403 & .171 & .164 & 2.355 & .022 \\
\hline PE & .401 & .083 & .404 & 4.847 & .000 \\
\hline EE & -.098 & .069 & -.125 & -1.426 & .159 \\
\hline SI & .472 & .060 & .693 & 7.817 & .000 \\
\hline FC & -.474 & .079 & -.627 & -5.974 & .000 \\
\hline TRUST & .237 & .177 & .097 & 1.337 & .187 \\
\hline ACCESS & .816 & .167 & .483 & 4.890 & .000 \\
\hline APPLICABILITY & -.440 & .148 & .221 & 2.961 & .005 \\
\hline
\end{tabular}

Table 7: Multiple regression analysis.

The predictors of the adoption and the use of e-medicine by medical doctors

Table 7 presents data on the predictors of the adoption and the use of e-medicine by the medical doctors. It shows that social influence $(\mathrm{B}=.693, \mathrm{t}=7.817)$, facilitating conditions $(\mathrm{B}=-.627, \mathrm{t}=-5.974)$, access $(\mathrm{B}=.483, \mathrm{t}=4.890)$, performance expectancy $(\mathrm{B}=.404, \mathrm{t}=4.847)$, applicability $(\mathrm{B}=.221, \mathrm{t}=2.961)$, and ICT skills $(\mathrm{B}=.164, \mathrm{t}=2.355)$ as the factors that predict the use of e-medicine by the doctors. The prediction relationship of facilitating conditions on the use of e-medicine by the doctors is found to be negative. The results suggest that social influence predicts the use of e-medicine by doctors in the context of Nigeria. This means that factors like subjective norm, social elements, image and attitude relate directly to the use rates of e-medicine. This finding is corroborated by [61] whose results indicated that behavioural intention to use smartphones was largely influenced by the attitude of nurses and doctors to adopt and use them. The researchers [61] adopted a TAM based theoretical framework and reported that academic research of smartphone adoption in healthcare is limited. The present study applied the UTAUT which is a more recent model to determine the use of e-medicine which covered a wider scope than smartphones' use in the health sector. The author [62] reported that acceptance behaviour is hypothesized to be influenced by a variety of factors, including attitudes, individual differences, social influence, beliefs and that attitudes predict intentions which predict behaviour. The authors [63] found evidence indicating that when technology adoption of older workers was compared to younger workers' adoption and usage, decisions were more strongly influenced by attitude toward using the technology. The authors [64] modified the UTAUT model to predict the variance intention $(44 \%)$ of the adoption of electronic records management (ERM) by doctors. The results from the present study indicate that the UTAUT model is relevant to explain technology adoption and use in the domain of medical doctors in Nigeria. The researchers [65] designed a framework for the evaluation of an adoption model that included both positive and negative user adoption factors of mobile technology by medical doctors. The results revealed that intrinsic motivation is a sufficient reason for adoption and a multi-faceted perceived overall risk factor as the main obstacle. The implications of the results by [65] were that when usefulness is less apparent, enjoyment may be a key factor for the adoption of mobile ICT for healthcare.

\section{Perceptions of adoption and the use of e-medicine}

Table 8 presents the results of the perceptions of the use of e-medicine by the doctors and the analysis shows that their perceptions using the weighted average estimated mean is 2.02 which is less than the expected mean of 2.41. For instance, the respondents (100\%) disagreed with the statement 'I am ready to offer specialized courses on Internet to be able to use e-medicine'. Seventy-three percent of the respondents also disagreed with the statement such as 'I do not prefer e-medicine because it demands high level ICT skills. These results suggest that the respondents have negative perceptions of the use of e-medicine in their medical practice. The authors [66] reported empirical and anecdotal findings based on the diffusion of innovation theory and suggested that the major uncertainties faced by physicians in the context of e-medicine center on quality of care, quality of service, and complexity issues (such as legal uncertainties) that make them have negative perceptions of technology adoption in medical care management and the resultant low use rates. The researchers [67] reported a survey conducted in Milan, Italy that indicated that despite the fact that $83 \%$ of respondents in that survey, had heard about telemedicine, many doctors considered telemedicine to be of limited interest and many physicians were not convinced that it could improve clinical practice. The study reported that these negative perceptions and attitudes were more common among doctors of higher seniority and reasoned that perhaps this was due to change management issues. The study recommended that to reduce such negative evaluations, better dissemination of information about the state of the art of research and development in telemedicine is needed.

\section{The use of e-medicine}

Table 9 shows the results of the use of e-medicine by doctors and the analysis indicates the weighted average estimated mean of the use of e-medicine is 0.97 which is less than the expected mean of 1.05 . For instance, the respondents (97\%) disagreed with a statement such as 'I use online communities for therapy, counseling of HIV patients, etcetera'. The respondents (77.7\%) disagreed with the statement 'I use the Internet for my medical practice'. Ninety-three percent of the respondents disagreed with the statement, 'I use ICT tools to communicate administrative staff in the hospital'. The results indicate a 
Citation: Olasina G, Popoola T (2014) Predictors of the Use of E-Medicine by Medical Doctors. J Health Med Informat 5: 166. doi:10.4172/21577420.1000166

Page 6 of 9

\section{Statement}

1). E-medicine helps to accomplish my work effectively and efficiently

2). It is difficult to use the Internet for medical practice work

3). I prefer to use e-medicine because it enhances my performance

4). E-medicine can transfer medical service to remote locations

5). I will find it easy and fluent to use ICT to manage patient information and retrieve data

6). I do not prefer e-medicine because it demands high level ICT skills

7). There is need to use e-medicine to raise doctors' skills in hospitals

8). I am ready to offer specialized courses on Internet, etcetera to be able to use e-medicine

9). I do not prefer e-medicine because it negatively affects the physician - patient relationship

10). I will advise patients and their relatives to use e-medicine (emailing of tests/results to patients, e-record case files, etc) for continuity of care (appointments etc)

Weighted Average Estimated Mean

\begin{tabular}{|c|c|c|c|c|}
\hline Agree & Disagree & Undecided & Mean & SD \\
\hline $62(60.2 \%)$ & $4(3.9 \%)$ & $37(35.9 \%)$ & 1.76 & 0.955 \\
\hline $44(42.7 \%)$ & $56(54.4 \%)$ & $3(2.9 \%)$ & 2.12 & 0.983 \\
\hline $56(54.4 \%)$ & $45(43.7 \%)$ & $2(1.9 \%)$ & 1.89 & 0.99 \\
\hline $61(59.2 \%)$ & $39(37.9 \%)$ & $3(2.9 \%)$ & 1.79 & 0.97 \\
\hline $38(36.9 \%)$ & $63(61.2 \%)$ & $2(1.9 \%)$ & 2.24 & 0.96 \\
\hline $27(28.2 \%)$ & $73(70.9 \%)$ & $3(2.9 \%)$ & 2.58 & 0.81 \\
\hline $71(68.9 \%)$ & $31(30.1 \%)$ & $1(1.0)$ & 1.61 & 0.92 \\
\hline $62(60.2)$ & $40(38.8 \%)$ & $0(0.0 \%)$ & 1.80 & 0.98 \\
\hline $21(20.4 \%)$ & $81(78.6 \%)$ & $1(1.0 \%)$ & 2.58 & 0.81 \\
\hline $59(57.3 \%)$ & $37(35.9 \%)$ & $7(6.8 \%)$ & 1.79 & 0.95 \\
\hline & & & & \\
\hline
\end{tabular}

Table 8: Perceptions.

\begin{tabular}{|c|c|c|c|c|c|}
\hline Statement & Agree & Disagree & Undecided & Mean & SD \\
\hline I use the Internet for my medical practice & $14(13.6 \%)$ & $80(77.7 \%)$ & $9(8.7 \%)$ & 1.06 & 0.327 \\
\hline I use ICT tools to interact officially with other medical professionals & $31(30 \%)$ & $70(68 \%)$ & $2(1.9 \%)$ & 0.98 & 0.326 \\
\hline I use ICT tools to manage patient information and retrieve data & $5(4.9 \%)$ & $98(95.1 \%)$ & $0(0 \%)$ & 0.99 & 0.327 \\
\hline Logging into several systems takes too long time & $76(73.8 \%)$ & $20(19.4)$ & $4(3.9 \%)$ & 0.99 & 0.330 \\
\hline I use clinical decision making systems & $15(14.6 \%)$ & $86(83.5 \%)$ & $2(1.9 \%)$ & 1.05 & 0.331 \\
\hline I use ICT to improve health outcomes & $25(24.3 \%)$ & $78(75.7 \%)$ & $0(0 \%)$ & 0.99 & 0.326 \\
\hline Routine tasks performance in a straightforward manner using the ICT such as EHR system & $11(10.7 \%)$ & $91(88.3 \%)$ & $1(0.97 \%)$ & 1.05 & 0.309 \\
\hline I find it easy and fluent to manage patient information using the information systems & $13(12.6 \%)$ & $90(87.4 \%)$ & $0(0 \%)$ & 1.05 & 0.332 \\
\hline The EHR system provides me appropriate feedback about the tasks it performs & $29(28.2 \%)$ & $70(68 \%)$ & $4(3.9 \%)$ & 0.75 & 0.300 \\
\hline I use Word processing and tools such as Powerpoint slides & 42 & 61 & $0(0 \%)$ & 0.97 & 0.330 \\
\hline I use email, SMS and other Internet tools to communicate with my patients & $12(11.7 \%)$ & $91(88.3 \%)$ & $0(0 \%)$ & 1.06 & 0.327 \\
\hline I use online communities for therapy, counseling of HIV patients, etc & $3(2.9 \%)$ & $100(97 \%)$ & $0(0 \%)$ & 1.00 & 0.331 \\
\hline I use ICT tools to communicate administrative staff in the hospital & $10(9.7 \%)$ & $93(90.3 \%)$ & $0(0 \%)$ & 0.86 & 0.319 \\
\hline I use ICT for communication with other medical professionals & $39(37.9 \%)$ & $74(71.9 \%)$ & $0(0 \%)$ & 0.91 & 0.327 \\
\hline $\begin{array}{l}\text { I use the Internet and ICT tools (laptops, desktops, printers, scanners, PDAs) for medical } \\
\text { work related purposes }\end{array}$ & $32(31.1 \%)$ & $71(68.9 \%)$ & $0(0 \%)$ & 0.89 & .318 \\
\hline Average Weighted Mean & & & & 0.97 & \\
\hline
\end{tabular}

Table 9: The use of e-medicine.

low use level of e-medicine by doctors. This result is expected. This may be due to the low level of ICT education that doctors received during their medical training. The study by Samuel et al. [68] suggested that the abilities to perform specific ICT skills of medical students were low. The authors [68] reported that (far less than 60\%) of the participants were able to perform the core specific ICT skills assessed in a study in Tanzania.

\section{Inhibitors}

Table 10 presents the analysis of the results on the inhibitors of the use of e-medicine by the doctors in Nigeria. The results indicate that the inhibitors include fears (privacy and security of data, $82.5 \%$ ), lack of e-medicine awareness (77.7\%), lack of ICT infrastructure (ICT tools, interconnectivity and power supply, $71.8 \%$ ), rapid changes in technology $(70.9 \%)$ and high cost of e-medicine applications and associated issues (69.9\%). The medical doctors express fears about privacy and security of their personal data and those of their patients. Overall, the results of the survey in regard to the research question that attempted to identify the major inhibitors of the use of e-medicine found that technological (infrastructure, skills) and behavioural factors were the important inhibitors. The author [69] reported that privacy and confidentiality were key factors that may inhibit the use of e-medicine. The author indicated that the application of ICT in the health sector is not a panacea for all the shortcomings of medicine but that ICT use in the health sector can improve patient-physician relations. Similar studies in Europe and the US seem to report the factors that inhibit the use of e-medicine to include ethics, legislation and issues of regulation. The researchers Smith and Manna [70] reported that consumers are armed and empowered with knowledge obtained via the Web and that this relieves some of the informational burden from the perspective of the medical care provider. The researchers explained that the practice of e-medicine may generate additional problems such as questionability of information on the Internet that may be incorrect and misleading. The authors [70] observed that the provision of medical information over the Internet is under-regulated. The researchers posit that a solution to this may be in the enactment of standards and regulations to protect consumers from activities such as unethical clinicians, inaccurate information, and unauthorized thirdparty use of confidential information. The researchers recommended the application of acceptable code of standards and ethics to increase customer loyalty and trust in e-medicine. Smith and Manna [70] concluded that the future benefits of e-medicine are far reaching regarding, physicians, patient education, patient support and the ability to connect physicians and patients. The researchers recommended the need for the phenomenon of e-medicine to self-regulate. Lastly the study reported that the success of e-medicine depended on trust by all stakeholders. Blumenthal [71] reported efforts at the promotion of awareness of the adoption of health information technology, especially electronic health records (EHRs) in the US. The author [71] revealed that perhaps $17 \%$ and $10 \%$, of physicians and hospitals respectively have basic EHRs. The researcher identified the significant barriers of the use of IT by physicians to include the substantial cost, 


\begin{tabular}{|c|c|c|c|c|c|}
\hline Inhibitors & Agree & Disagree & Undecided & Mean & SD \\
\hline High cost & $72(69.9 \%)$ & $29(28.2 \%)$ & $2(1.9 \%)$ & 2.42 & 0.90 \\
\hline Lack of training & $67(65 \%)$ & $30(29.1 \%)$ & $6(5.8 \%)$ & 2.24 & 0.96 \\
\hline Lack of interest & $41(39.8 \%)$ & $62(60.2 \%)$ & $0(0.0 \%)$ & 1.80 & 0.98 \\
\hline Lack of ICT infrastructure-ICT tools, interconnectivity, power supply, & $74(71.8 \%)$ & $28(27.2 \%)$ & $1(1.0 \%)$ & 2.45 & 0.89 \\
\hline Lack of e-medicine awareness & $80(77.7 \%)$ & $22(21.4 \%)$ & $1(1.0 \%)$ & 2.56 & 0.82 \\
\hline Rapid changes in technology & $73(70.9 \%)$ & $27(26.2 \%)$ & $3(2.9 \%)$ & 2.58 & 0.81 \\
\hline Difficulty of use of e-medicine & $59(57.3 \%)$ & $37(35.9 \%)$ & $7(6.8 \%)$ & 1.79 & 0.95 \\
\hline Social influence-friends, colleagues, society, patients & $68(66.0 \%)$ & $34(33.0 \%)$ & $1(1.0 \%)$ & 1.67 & 0.94 \\
\hline Fears for privacy and security of data & $85(82.5 \%)$ & $16(15.5 \%)$ & $2(1.9 \%)$ & 1.33 & 0.73 \\
\hline
\end{tabular}

Table 10: Inhibitors of the use of e-medicine.

the perceived lack of financial return from investing in them, the technical and logistic challenges such as installation, maintenance, and regular updates and consumers' and physicians' concerns about the privacy and security of electronic health information. Buntin et al. [72] reported that dissatisfaction of physicians with electronic health records, lack of technology support, e-prescribing took longer than conventional prescription and high cost of implementations as the major inhibitors of technology adoption by medical doctors. Buntin et al. [72] highlighted the need for studies that document the challenging aspects of implementing health information technology more specifically and how these challenges may be addressed.

\section{Summary Table}

\section{What was known before}

- Theories of technology adoption have been applied in the context of learning (e-learning), industry, SMEs and government (e-governance).

- Limited studies have applied these theories in the context of medical doctors in Nigeria.

- The TAM and the UTAUT have been reported as successful in predicting specific aspects of the adoption and the use of technology in the contexts of e-learning, industry, SMEs and e-governments in many countries.

- The applicability of these models have not been adequately tested and validated in the domains of medical doctors and other medical professionals in their use of e-medicine platforms.

\section{What the study added to knowledge}

- The applicability of the UTAUT model to the use of e-medicine within the context of socio-economic and health infrastructural environment in Nigeria.

- Contributions to improved understanding of theory suggesting that the UTAUT can be extended and made more robust by inclusion of variables like socio-economic factors in the context of medical doctors in Nigeria.

- Of the four constructs of the UTAUT model (performance expectancy, effort expectancy, social influence and facilitating conditions) and their hypothesized relationships with behavioural intention, technology adoption and use, social influence, facilitating conditions and performance expectancy have been found to predict the use of e-medicine in the context of the study.

- Indication that the other effort expectancy may not be relevant to explain the use of technology in Nigeria.

\section{Conclusion}

The purpose of the study was to investigate the use of e-medicine by medical doctors in Nigeria. The study had the following research questions: (1) What are the predictors of the use of e-medicine by medical doctors? (2) What are the perceptions of the use of e-medicine? (3) To what extent do doctors adopt the use of e-medicine? (4) What are the inhibitors of the use of e-medicine? The key results indicate that factors such as social influence (subjective norm, social elements, image and attitude), facilitating conditions (organizational impact, technical support, infrastructure and awareness), access, performance expectancy, applicability and ICT skills are the critical factors that predict the use of e-medicine by medical doctors in Nigeria. The prediction relationship of facilitating conditions is found to be negative. The implication of these findings are that despite the widely reported influence of factors such as perceived usefulness and perceived ease of use as drivers of usage intentions of technology in the context of SMEs, e-learning, wireless and mobile telephony, the variable, social influence and personal traits such as individual innovativeness are potentially important predictors of the use of e-medicine by medical doctors in Nigeria. This conclusion has implications for the theory of technology adoption such as the UTAUT. Perhaps the most important contribution of this study in the regard the UTAUT is the suggestion to strengthen the model by social influence constructs and environmental factors to better explain technology use in the context of medical doctors in Nigeria. Menachemi et al. [66] reported that for telemedicine systems to increase penetration throughout the existing healthcare system, issues such as different values, experiences, and motivations guiding the users' adoption and use decisions must be addressed. As suggested by Menachemi et al. [66] the communication of e-medicine awareness should be targeted at meeting needs such as improvement in the overall quality of care provided increased efficiency with which physicians perform their tasks and the promotion of collaboration among physicians.

The analyses of the results suggest that medical doctors in Nigeria have low perceptions and negative perceptions of the use of e-medicine which may be as a result of poor ICT infrastructure and the training of the doctors and other medical workers which may not be rich in ICT content. The initiatives to increase the rate of use of e-medicine by the doctors may require not only improved provision of financial and human resources to be supportive of e-medicine but a conscious effort to expose the doctors to the relative advantages of e-medicine in Nigeria and thereby increase doctors' perceived ease of use and perceived usefulness of e-medicine. The infrastructure to support this locally driven campaign must be put in place before the deployment of e-medicine technology. Despite the results that indicate negative attitudes and the low perceptions of e-medicine of doctors, there is the suggestion that doctors may use e-medicine in the future. The conclusion is that with the motivation of doctors more of them 
may adopt and use e-medicine. Policy interventions and awareness creation may help increase the numbers of medical doctors that use e-medicine. The intended interventions and strategies should make the medical doctors to be truly mobile workers from among themselves. The administrators of health institutions should provide facilitating conditions and awareness programmes that will stress the applicability of the use of ICT in medical service delivery in Nigeria. The conclusion regarding the inhibitors of the use of e-medicine is that the identified issues such as fears, lack of e-medicine awareness, rapid changes in technology and high cost of e-medicine applications and associated issues often lead doctors to be less likely to reach positive conclusions about the use of e-medicine. These inhibitors are better addressed by appropriated strategies, devises and policies aimed at improving the field of medicine and medical practice by introducing e-medicine applications in the context of Nigeria.

\section{References}

1. Catwell L, Sheikh A (2009) Evaluating eHealth interventions: the need for continuous systemic evaluation. PLoS Med 6: e1000126.

2. Wears RL, Berg M (2005) Computer technology and clinical work: still waiting for Godot. JAMA 293: 1261-1263.

3. Straub E (2009) Understanding technology adoption: Theory and future directions for informal learning, Review of Educational Research 79: 625-649.

4. Idowu B, Adagunodo R, Adedoyin R (2006) Information technology infusion model for health sector in a developing country: Nigeria as a case. Technol Health Care 14: 69-77.

5. Bakare A, Olubokun S (2011) Health care expenditure and economic growth in Nigeria: An empirical study, Journal of Emerging Trends in Economics and Management Sciences 2: 83-87.

6. Eno V (2008) Governance constraints and health care delivery in Nigeria: The case of primary health care services in Akwalbom State. Public Administration and Management 15: 342-364.

7. Jacobs B, Price N (2004) The impact of the introduction of users fees at district hospital in Cambodia. Health policy plan 19: 310-321.

8. Menachemi N, Burke DE, Ayers DJ (2004) Factors affecting the adoption of telemedicine--a multiple adopter perspective. J Med Syst 28: 617-632.

9. Tung F, Chang S, Chou C (2008) An extension of trust and TAM model with IDT in the adoption of the electronic logistics information system in HIS in the medical industry. International journal of medical informatics 77: 324-335.

10. Smith JJ, Mallard-Smith RJ, Beattie V, Beattie DK (2003) Use of information technology in general practice. J R Soc Med 96: 395-397.

11. Coiera E (1995) Medical informatics. BMJ 310: 1381-1386.

12. Asangansi I, Adejoro O, Farri O, Makinde $O$ (2008) Computer use among doctors in Africa: Survey of trainees in a Nigerian teaching hospital. Journal of Health Informatics in Developing Countries 2: 10-14.

13. Smith A, Manna D (2004) Exploring the trust factor in e-medicine. Online Information Review 28: 346-355.

14. Perloff R, Bonder B, Ray G, Ray E, Siminoff L (2006) Doctor-patien communication, cultural competence, and minority health theoretical and empirical perspectives. American Behavioral Scientist 49: 835-852.

15. Anderson JG, Rainey MR, Eysenbach G (2003) The impact of CyberHealthcare on the physician-patient relationship. J Med Syst 27: 67-84.

16. Didham R, Martin I, Wood R, Harrison K (2004) Information Technology systems in general practice medicine in New Zealand. N Z Med J 117: U977.

17. Ozumba B (2002) The World Congress on the Internet in Medicine MEDNET.

18. (Mukherjee A, McGinnis J (2007) E-healthcare: An analysis of key themes in research. International Journal of Pharmaceutical and Healthcare Marketing 1: 349-363.

19. SachdevaS (2002) e-Governance strategy in India. White Paper on e-Governance strategy in India 1-35.
20. The health on the net winter, 2004-2005 survey responses.

21. Boyer C, Baujard V, ScherrerJ, Appel R (1998) HON's third survey on the usage of the Internet for medical and health Internet purposes. The Third Annual World Congress on the Internet in Medicine, London, UK.

22. AbdGhani M, Bali R, Naguib R, Marshall I (2008) Electronic health records approaches and challenges: a comparison between Malaysia and four East Asian countries.Int J Electron Healthc 4: 78-104.

23. Khudair A (2008) Electronic health records: Saudi physicians' perspective 1-7.

24. Aärimaa M (2004) Telemedicine--contribution of ICT to health. Stud Health Technol Inform 100: 111-116.

25. Protti D, Bowden T, Johansen I (2008) Adoption of information technology in primary care physician offices in New Zealand and Denmark, part 3: Medical record environment comparisons. Informprim care 16: 285-290.

26. Bennett N, Casebeer L, Kristofco R, Strasser S (2004) Physicians' Internet information-seeking behaviours. J Contin Educ Health Prof 24: 31-38.

27. Colpaert K, Decruyenaere J (2009) Computerized physician order entry in critical care. Best Pract Res Clin Anaesthesiol 23: 27-38.

28. Masters K (2008) For what purpose and reasons do doctors use the Internet: a systematic review. Int J Med Inform 77: 4-16.

29. Ityavyar DA (1987) Background to the development of health services in Nigeria. Soc Sci Med 24: 487-499.

30. Onokerhoraye AG (1976) A suggested framework for the provision of health facilities in Nigeria. Soc Sci Med 10: 565-570.

31. Olasina G (2011) The use of web 2.0 tools and social networking sites by librarians, information professionals, and other professionals in workplaces in Nigeria. PNLA Quarterly 75: 11-43.

32. Yekini N, Rufai M, Adetoba B , Akinwole A, Ojo O (2012) ICT "tools" for poverty eradication and economic growth in Nigeria, Greener Journal of Educational Research 2: 013-019.

33. ITU (2008) Trends in telecommunication reform. Promoting universal access to ICTs, Practical Tools for Regulators, Geneva.

34. Ozumba B (2002) The world congress on the internet in medicine.

35. Fischer S, Stewart TE, Mehta S, Wax R, Lapinsky SE (2003) Handheld computing in medicine. J Am Med Inform Assoc 10: 139-149.

36. Sandars J, Morrison C (2007) What is the Net Generation? The challenge for future medical education. Med Teach 29: 85-88.

37. Andreassen $\mathrm{H}$, Trondsen M, Kummervold $\mathrm{P}$, Gammon G, Hjortdahl $\mathrm{P}$ (2006) Patients who use e-mediated communication with their doctor: New constructions of trust in the patient-doctor relationship, Qual Health Res 16 238-248.

38. Palen TE, Ross C, Powers JD, Xu S (2012) Association of online patient access to clinicians and medical records with use of clinical services. JAMA 308: 2012 2019.

39. Greenberg D, Pliskin J (2008) Adoption and use of new medical technology at the hospital level. Risk Management 10: 120-134.

40. Bagozzi R (2007) The legacy of the technology acceptance model and a proposal for a paradigm shift, Journal of the Association for Information Systems 8: 244-254

41. Sloan F (2000) Not-for-profit ownership and hospital behaviour, Handbook of health economics 1: 1141-1174.

42. Folland S, Goodman A, Stano M (2007) The economics of health and health care (Volume 6). Pearson Prentice Hall, Upper Saddle River, NJ.

43. Davis F (1989) Perceived usefulness, perceived ease of use and user acceptance of information technology. MIS Quarterly 13: 319-340.

44. Chau $P$ (1996) An empirical assessment of a modified technology acceptance model, Journal of Management Information Systems 13: 185-204.

45. Bagozzi R, Kimmel S (1995) A comparison of leading theories for the prediction of goal directed behaviours, British Journal of Social Psychology 34: 437-461.

46. Bagozzi R, Wong N, Abe S, Bergami M, (2000) Cultural and situational contingencies and the theory of reasoned action: Application to fast food restaurant consumption. Journal of Consumer Psychology 9: 97-106. 
Citation: Olasina G, Popoola T (2014) Predictors of the Use of E-Medicine by Medical Doctors. J Health Med Informat 5: 166. doi:10.4172/21577420.1000166

47. Venkatesh V, Morris M, Davis G, Davis F (2003) User acceptance of information technology: Toward a unified view, MIS Quarterly 27: 425-478

48. Oshlyansky L, Cairns P, Thimbleby H (2007) Validating the unified theory of acceptance and use of technology (UTAUT) tool cross-culturally.Electronic Workshops in Computing 2: 83-86.

49. Cody-Allen E, Kishore R (2006) An extension of the UTAUT model with e-quality, trust, and satisfaction constructs. ACM SIGMIS CPR conference on computer personnel research: Forty four years of computer personnel research: achievements, challenges and the future, Claremont, California, USA.

50. Chiemeke S, Evwiekpaefe A (2011) A conceptual framework of a modified unified theory of acceptance and use of technology (UTAUT) model with Nigerian factors in e-commerce adoption. Educational Research 2: 1719-1726.

51. Kijsanayotin B, Pannarunothai S, Speedie S(2009) Factors influencing health information technology adoption in Thailand's community health centers: Applying the UTAUT model, International Journal of Medical Informatics 7: 404416.

52. Dansky KH, Gamm LD, Vasey JJ, Barsukiewicz CK (1999) Electronic medical records: are physicians ready? J Healthc Manag 44: 440-454.

53. Ganapathy K (2011) E-medicine: transforming healthcare with information and communication technology. MJAFI 67: 106-107.

54. van der Meijden MJ, Tange H, Troost J, Hasman A (2001) Development and implementation of an EPR: how to encourage the user. Int J Med Inform 64: 173-185.

55. Buysschaert $P$ (2009) Assessing the opportunities and the pertinence of eHealth in developing countries. Information Society and Media, European Commission.

56. Joint United Nations Programme on HIVIAIDS and World Health Organization (2006) AIDS epidemic update.World Health Organization.

57. Ruxwana NL, Herselman ME, Conradie DP (2010) ICT applications as e-health solutions in rural healthcare in the Eastern Cape Province of South Africa. HIM J 39: 17-26.

58. Robson C (1997) Real world research Oxford: Blackwell 306-308.
59. Schwandt T (1989) Solutions to the paradigm conflict: Coping with uncertainty, Journal of Contemporary Ethnography 17: 379-407.

60. Nunnally J (1978) Psychometric theory: (edition $2^{\text {nd }}$ stden), McGraw-Hill, New York.

61. Park Y, Chen J (2007) Acceptance and adoption of the innovative use of smartphone, Industrial Management and Data Systems 107:1349-1365.

62. Agarwal R (2000) Individual acceptance of information technologies, Framing the domains of IT management: Projecting the future through the past 85-104.

63. Venkatesh V, Morris M (2000) Why don't men ever stop to ask for directions? Gender, social influence, and their role in technology acceptance and usage behaviour MIS quarterly 115-139.

64. Venkatesh V, Sykes T, Zhang X (2011) Just what the doctor ordered': A revised UTAUT for EMR system adoption and use by doctors. In System Sciences (HICSS) 44th Hawaii International Conference on IEEE.

65. Cocosila M, Archer N (2010) Adoption of mobile ICT for health promotion: an empirical investigation. Electronic Markets 20: 241-250.

66. Menachemi N, Burke DE, Ayers DJ (2004) Factors affecting the adoption of telemedicine--a multiple adopter perspective. J Med Syst 28: 617-632.

67. Gaggioli A, di Carlo S, Mantovani F, Castelnuovo G, Riva G (2005) A telemedicine survey among Milan doctors. J Telemed Telecare 11: 29-34.

68. Samuel M, Coombes JC, Miranda JJ, Melvin R, Young EJ, et al. (2004) Assessing computer skills in Tanzanian medical students: an elective experience. BMC Public Health 4: 37.

69. Hersh W (2004) Health care information technology: progress and barriers. JAMA 292: 2273-2274

70. Smith A, Manna D (2004) Exploring the trust factor in e-medicine. Online Information Review 28: 346-355.

71. Blumenthal D (2009) Stimulating the adoption of health information technology. N Engl J Med 360: 1477-1479.

72. Buntin M, BurkeM, Hoaglin M, Blumenthal D (2011) The benefits of health information technology: A review of the recent literature shows predominantly positive results. Health Aff 30:464-471. 